\title{
Faculty Epistemological Beliefs and the Influence of Professional Development
}

\author{
Lloyd M. Mataka ${ }^{1 *}$, Jon C. Saderholm², Tracy Hodge ${ }^{3}$
}

${ }^{1}$ Department of Natural Science and Mathematics, Lewis-Clark State College, Lewiston, Idaho, United States of America, ${ }^{2}$ Department of Education, Berea College, Berea, Kentucky, United States of America, ${ }^{3}$ Department of Physics, Berea College, Berea, Kentucky, United States of America

*Corresponding Author: Immataka@Icsc.edu

\section{ABSTRACT}

This study explored the epistemological beliefs of the science faculty at a small liberal arts college in the Southern United States and investigated the effect of a Faculty Learning Community (FLC) professional development (PD). The teacher beliefs interviews (Luft and Roehrig, 2007) were used to investigate epistemological beliefs of faculty from various science, technology, engineering, and mathematics (STEM) disciplines for three semesters. The faculty members were grouped into two categories: Those who participated in PD (treatment group) and those who did not (comparison group). Further, classes for all the faculty members who participated in the interviews were observed during the same period to compare beliefs and practices. Reformed teacher observation protocol (Piburn and Sawada, 1995) was used to rate the observations. Results indicate the STEM faculty at this college had transitional beliefs. Further, a significant difference was observed between the classroom observations of FLC participants and the comparison group. Significantly, a high correlation was found between faculty beliefs and practice. Results from this study add to the current understanding of faculty beliefs and practice.

KEY WORDS: epistemological beliefs; science, technology, engineering, and mathematics; teacher beliefs interviews; faculty learning community; posttest, faculty

\section{INTRODUCTION}

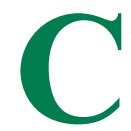
ollege science faculty has a critical role in developing students who are curious, has good problem-solving skills, and can apply their knowledge to real-world phenomena (Gabr \& Mohammed, 2011; Gallagher \& Stepien, 1992). An effective college faculty will devise instructional strategies that enhance these critical skills in students. Beliefs about teaching are important because they affect how faculty understand and implement their curriculum (Fletcher, 2006). Beliefs can affect teaching styles and how faculty manage their classrooms (Jones \& Carter, 2007; Pajares, 2008; Richardson, 1996). Because of this, many colleges have embarked on professional development (PD) activities with the aim of improving students' learning outcomes (Beach \& Cox, 2009; Brydges et al., 2013; Harris \& Cullen, 2008). These faculty PD activities need to be based on an understanding of where the faculty is in terms of teaching, to align the activities to the faculty needs. Studying faculty beliefs about teaching may provide a basis for appropriate PD plans by providing PD designers with an understanding of where the faculty is coming from and where they need to take them. Further, research has shown that faculty beliefs usually align with teaching practices (Addy, 2011; Jackson, 2010). Therefore, information on faculty beliefs about teaching may provide a route to understanding faculty teaching practices. In this study, we used the teacher beliefs interview (TBI) (Luft \& Roehrig, 2007) to investigate the epistemological beliefs of faculty at a small, liberal arts college in the Southern United States. We also compared the faculty's epistemological beliefs to their classroom practices using the Reformed Teaching Observation Protocol (RTOP) (Piburn \& Sawada, 1995).

\section{LITERATURE REVIEW}

\section{PD with Faculty Learning Communities (FLC)}

PD incorporating a FLC is a two-step process that not only involves a workshop or a PD activity but also provides support to the participants through weekly or biweekly meetings. Since the early 2000s, PD with FLC programs has increased in number in North America (Richlin \& Essington, 2004). Some studies have shown that faculty who are involved in these activities adopted nontraditional teaching practices while others planned to use the practices in their subsequent courses (Beach \& Cox, 2009; Brydges et al., 2013). It is possible that, among other factors, this is due to improved faculty epistemological beliefs. In this study, we hoped to extend this understanding by investigating faculty epistemological beliefs after participating in a PD with FLC.

\section{Epistemological Beliefs}

Berding et al. (2017) define epistemological beliefs as "beliefs about knowing and knowledge" (p. 103). Other researchers have labored to explore the term "beliefs" 
with varied definitions. Beliefs have been equated to both attitudes (Garmon, 2004) and theories and philosophies (Simmons et al., 1999). Kagan (1990) asserts that beliefs are instrumental in the decision-making process that may lead to a specific action by an individual. Beliefs can be described for both individuals (Nespor, 1987) and groups (Fishbein \& Ajzen, 1975). Researchers in education have been intrigued by both teachers' (Speer, 2005) and students' (Pehkonen \& Törner, 1996; Schoenfeld, 1983) beliefs to explain the observed classroom behaviors. In his analysis, Österholm (2010) concluded that "the main topic when defining beliefs is to decide, based on what is being studied, which perspective is the most suitable one when defining beliefs, the social or the individual, and then to be consistent within this one perspective" (p. 161). It is thus clear that no agreement on a single definition of beliefs has been reached.

Ismail et al. (2013) describe epistemological beliefs as "beliefs about the nature of knowledge and learning" (p. 140). Understanding an individual's epistemological beliefs is a complex process because multiple beliefs make up an individual's personal epistemology (Schommer et al., 1992). Epistemological beliefs are dynamic in that changes may occur over time (Ismail et al., 2013). That is, a teacher who believes in one approach of teaching practice may change these beliefs when favorable conditions for the change arise. Further, understanding faculty epistemological beliefs can serve as a vehicle in terms of mobilizing appropriate resources for PD. That is, it is easy to have a focused view of what type of PD is needed for specific individuals or groups of individuals.

In one study, Schramm-Possinger (2015) grouped instructor beliefs in terms of custodial and humanistic orientation. On the one hand, the custodial beliefs focus on the teacher-directed types of activities that do not give students more autonomy in their learning. On the other hand, humanistic approaches create a challenging environment that enables students to become more independent, self-regulated, more self-disciplined, and more engaged in their learning activities. Therefore, the faculty's beliefs on classroom engagements need closer scrutiny. Luft and Roehrig (2007) extended the classification of teacher's epistemological beliefs into five categories: Traditional, instructive, transitional, responsive, and reformed. The first two categories represent teacher-centered beliefs, and the last two represent student-centered beliefs. The transitional beliefs are the intermediate between the two ends. In this case, teachers are transitioning from having teacher-centered toward student-centered beliefs. Using this categorization, these authors developed seven interview questions to capture teachers' epistemological beliefs; TBI (Luft \& Roehrig, 2007). The seven interview questions capture epistemological beliefs about (1) teacher's role, (2) student learning and understanding, and (3) teachers' decision about content.

\section{Research on Teacher Epistemological Beliefs}

Some authors have advocated investigating both epistemological beliefs and teachers' practice. For instance, Hashweh (1996) categorized teachers' beliefs into naïve (teacher-centered) and sophisticated (student-centered). Through a literature review, Kember (1997) found that most researchers concur with Hashweh's categorization of the teachers' conceptions or beliefs. Faculty who hold naïve views or beliefs about teaching put themselves at the center of learning. That is, the faculty believes that they hold important knowledge which is to be transmitted to the students (Varnava-Marouchou, 2007). On the contrary, faculty with sophisticated views believes in facilitating students' learning by providing opportunities for students to develop meaning from the learning process. Hashweh (1996), and Kember and Kwan (2000) found a positive relationship between teachers' epistemological beliefs and practice. That is, teachers with reformed beliefs had better ways to enhance students' conceptual change than their counterparts with non-reformed epistemological beliefs.

Using the TBI, Fletcher (2006) found that pre-service secondary teachers had more student-centered beliefs while in an induction program, but these beliefs changed toward teacher-centered in the $1^{\text {st }}$ year of their teaching. This change was attributed to contextual factors. Further, Luft and Roehrig (2007) found that beginning secondary school teachers had viewed at the instructive level, which tended to move toward traditional for those in general education programs and toward transitional for those in science-focused programs. These authors recommended specialized support to help modify teachers' beliefs to the more reformed levels. Further, Addy (2011) used TBI to assess beliefs of faculty with educational specialties (scientists who focus on science education). In this study, Addy (2011) found that the college faculty had epistemological beliefs ranging between transitional and reformed. Moreover, these beliefs depended on class size. That is, faculty teaching smaller classes had more reformed beliefs than those teaching larger classes. That is, faculty teaching smaller classes had more reform-based beliefs than those teaching larger classes. The author concluded that these faculty members had appropriate training that equipped them with reformed beliefs about teaching.

Although TBI has been extensively used on secondary school teachers' epistemological beliefs (Fletcher, 2006; Luft \& Roehring, 2007; Luft \& Zhang, 2014), there are fewer reported studies on its use with college faculty (Addy, 2011). Specifically, Addy (2011) and Addy et al. (2015) used it on faculty with education specialty and argued for more research in this field. This study addresses that need as we use TBI to explore liberal arts college science, technology, engineering, and mathematics (STEM) faculty beliefs about teaching and learning. Furthermore, we compare the beliefs of faculty who participated in the PD with FLC and those who did not, and we compare the faculty epistemological beliefs with their practice. Consequently, this study answers three research questions:

- What are the epistemological beliefs of science faculty at a Southern United States liberal arts college?

- What is the impact of participating in PD on faculty epistemological beliefs? 
- What is the relationship between faculty epistemological beliefs and teaching practice?

\section{METHODOLOGY}

\section{Research Design}

We applied a quasi-experimental post-test only methodology for this study. The methodology comprised a mixed methods study that reported the same interview data, both quantitatively and qualitatively. The participants were a combination of tenured and pre-tenure faculty who teach courses in the disciplines of biology, chemistry, physics, mathematics, and computer science. The STEM courses had an average of 25 students in each class. An informed consent process was completed to ensure, the ethics of the research are addressed.

\section{PD}

We conducted a two-stage faculty development model that comprised a 4-day course redesign workshop followed by on-going participation in a FLC during the following academic year. During summer workshops, we exposed the participants to learner-centered pedagogies (Fink, 2003) while redesigning the syllabus for a course they intended to teach the following academic year. Workshop themes included motivation, significant learning goals and objectives, learnercentered assessment, major non-traditional assignments, and objective-assignment alignment. Although all 28 STEM faculty members were invited to participate, only 19 participated in the interviews. Of the 19, 13 participated in the PD, while 11 were in the comparison group to make a total of 24 participant interviews. Five members in the experimental group were interviewed both in the comparison group before participating in the $\mathrm{PD}$ and also in the experimental group after participating in the PD, for a total of 24 interviews. The participants represent all STEM disciplines at the college and include a broad mix of pre- and post-tenure faculty members (Table 1). There were two cohorts of faculty members who participated in the workshop, as shown in Table 1.

We collected information on the characteristics of the participants in the PD and comparison groups (Table 2).

\section{The Interview Process}

The TBI was used to determine faculty epistemological beliefs. The TBI was developed by Luft and Roehring (2007) to "describe and define various beliefs held by pre-service, beginning/induction, and experienced science teachers" (p. 38). During the interviews, 13 faculty members (including the five who were interviewed before and after PD) were FLC participants while 11 were from the comparison group.

\section{Classroom Observations}

The observations were conducted in a series of steps. The first stage involved training to use the RTOP (Piburn and Sawada, 1995) by watching prescribed training videos, rating them, and comparing our rating to the suggested rating. The second stage of training involved the two researchers simultaneously observing five classes and rating the observations separately for comparisons. Then, the differences were discussed while referring to the training video to ensure more accurate ratings of the RTOP. Then, individual researchers observed and rated the remaining classes. In total, 24 faculty members were observed, 13 in the treatment, and 11 in the control section, resulting in a total of 56 observations because there was more than one observation for each participant. The five faculty members participating in both the comparison group and the treatment group are included in the totals for each group.

We conducted at least two classroom observations for each faculty depending on their cohorts: Fall 2014, Spring 2015, and Fall 2015. Observers took running record notes describing both faculty and student activity for an entire class period. Extemporaneous side notes were added describing observer perception about the instruction. For instance, observers might have noted missed probing questions or accessing students' prior knowledge. During the first-pass over the notes, the researchers formed a rough understanding of how the lesson was taught. The notes were read again before receiving a rating. The rating process involved checking and rechecking the observation transcripts.

\section{RESULTS}

We conducted a normality test to determine if the TBI scores were modeled by a normal distribution. This is necessary when using parametric tests. The null hypothesis was that the TBI scores were normally distributed. Shapiro's Wilk was found as $\mathrm{W}=0.96, \rho=0.43$, and hence, we accepted the null hypothesis. Using ANOVA, teaching experience $(\mathrm{F}=3.66$, $\mathrm{p}=0.04$ ) significantly affected faculty epistemological beliefs. However, faculty discipline $(\mathrm{F}=0.653, \mathrm{p}=0.64)$ and tenure status $(\mathrm{t}=1.02, \mathrm{p}=0.38)$ had no influence on the TBI scores.

Table 1: Participants and their disciplines

\begin{tabular}{lcccc}
\hline Discipline & \multicolumn{2}{c}{ Comparison group } \\
\cline { 2 - 4 } & Participants & 2014 Cohort & 2015 Cohort & \multicolumn{1}{c}{ Corticipants } \\
\hline Biology & 2 & 1 & 1 & 3 \\
Chemistry & 3 & 2 & 1 & 3 \\
Computer science & 3 & 2 & 1 & 3 \\
Math & 2 & 2 & 1 & 1 \\
Physics & 3 & 8 & 5 & 11 \\
Total & 13 & 1 & 1 & 1 \\
\hline
\end{tabular}




\section{Instructor's General Epistemological Beliefs}

The first research question was "What are the epistemological beliefs of science faculty at a small, Southern US liberal arts college?" To answer this research question, the mean TBI score (out of 30) was calculated. The mean score was $17.8 \pm 3.6$ with a median score of 18.0. This mean score shows that the faculty had responses consistent with transitional beliefs, according to Luft and Roehring (2007). Of the 24 faculty interviews, seven

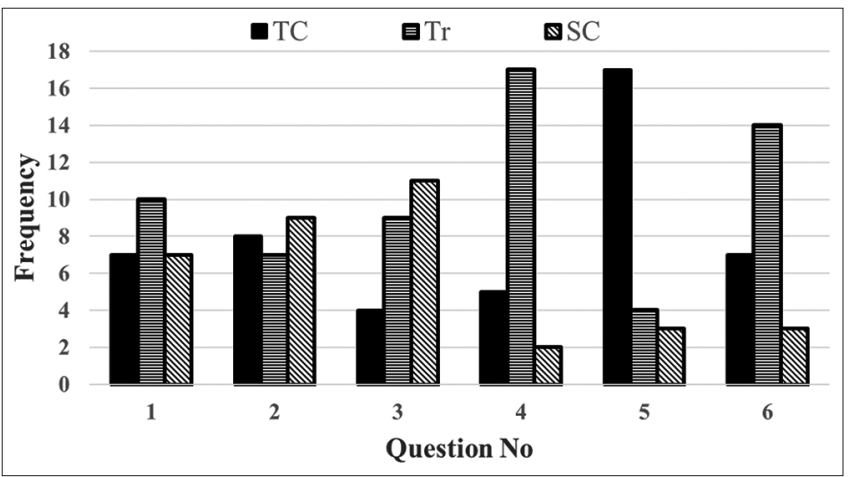

Figure 1: The frequency of faculty epistemological beliefs for each teacher beliefs interview question $(n=24)$. TC: Teacher-centered; Tr: Transitional; SC: Student centered

\section{Table 2: Participants characteristics}

\begin{tabular}{lcc}
\hline $\begin{array}{l}\text { Faculty } \\
\text { characteristics }\end{array}$ & $\begin{array}{c}\text { PD participants } \\
(\mathbf{n}=13)\end{array}$ & $\begin{array}{c}\text { Comparison group } \\
(\mathbf{n}=\mathbf{1 1})\end{array}$ \\
\hline Mean teaching years & $13.1 \pm 7.3$ & $10.8 \pm 7.9$ \\
Tenured & 8 & 6 \\
Non-tenured & 5 & 5 \\
Male & 8 & 9 \\
Female & 5 & 2 \\
\hline
\end{tabular}

had beliefs consistent with instructive level, while 15 had transitional beliefs with the remaining two between responsive and reformed beliefs.

Figure 1 shows the distribution of faculty responses among the five categories of the TBI for each question. For this study, traditional and instructive beliefs have been grouped into a category named "teacher-centered beliefs," while responsive and reformed beliefs have been renamed "student-centered beliefs." Transitional beliefs remain as such.

The figure shows that teacher-centered beliefs dominated question 5 shown below:

- Question 5: How do you decide when to move on to a new topic?

Further, transitional level beliefs dominated questions 1,4 , and 6. The questions are as follows:

- Question 1: How do you describe your role as a teacher?

- Question 4: How do you maximize learning?

- Question 6: How do you know when students are learning/ understand?

Questions 2 and 3 had responses dominated by studentcentered beliefs. The questions are as follows:

- Question 2: How do you decide what to teach?

- Question 3: How do your students learn science best?

Table 3 provides a sample quote for each of the questions and the rating of that quote.

\section{Epistemological Beliefs Based on Student Interest versus Teacher Interest}

This section of our analysis sought to find out how the faculty beliefs displayed teacher interest compared to student interest. We defined teacher interest beliefs as those that did not explicitly

\section{Table 3: Sample quotes and faculty ratings}

\begin{tabular}{ll}
\hline Question & Sample quote \\
\hline How do you describe your & CHM3: I think of myself as, I guess, a few different roles. I am an instructor for one. I am a presenter of \\
role as a teacher? & important topics in chemistry, but I am also a helper on their way to learn whatever that way is. \\
How do you decide what & CHM4: Well, I think, you know, in the classes that I teach are already pretty well clearly delineated... At
\end{tabular}

to and what not to teach?

the end of the class, I use the ACS standardized physical chemistry exams for both thermal and quantum. And so, in that sense, there is which has essentially told us what to cover. So, it's an agreed-upon canon. So, what we do in that class, I would say is very prescribed.

How do your students learn science best?

How do you maximize learning?

How do you decide when to move on to a new topic?

How do you know when students are learning?
MAT1: I often say in class; you may have heard me say. "Today is a good day to be wrong." Right, so get up there, show me what you got, report out to your group or report to the class and, you know, if you are wrong, we will all be supportive of you and we will help to find, you know, those mistakes.

PHY1: So, I think that's what I have done up to this point, the concept questions, the peer instruction kind of, stop and think about this and discuss it with your neighbor, I think is much better than just passively listening and then taking the entire class period out and saying now you are going to solve this problem with your group. I think they learn much from that than they do it from me solving a problem at the board. BIO2: Some of it is dictated by the schedule. Some of it, I am bending my schedule a little bit because, again, this is the $1^{\text {st }}$ time I have taught this course. So, I am learning that, ok we need to stop, and if they are not, they are having trouble with the clicker questions, they are not answering questions correctly that I am asking them, we are having trouble with the in-class activities, then I know to slow down and that we need a little bit more time with this subject.

CSC2...it seems students might make an incredible contribution to the discussion and then I will see in class that that student was prepared or they won't contribute substantially if they don't know."
$\mathrm{SC}$

$\operatorname{Tr}$

$\operatorname{Tr}$ TC: Teacher-centered, Tr: Transitional, SC: Student-centered 
display or encourage student active engagement. These beliefs displayed a focus on finishing the course versus providing specific experiences to students. Schramm-Possinger (2015) referred to these beliefs as "custodial" student interest beliefs were defined as those that focused on providing experiences that align with students' interest and get them more involved in the learning process. In this case, the learning process is as important as the end product of knowledge acquisition. Analysis of the data indicated a spectrum of epistemological beliefs between student interest and teacher interest. Figure 2 shows a breakdown of data demonstrating these beliefs.

Only three questions were included because of their relevance to this subsection, as shown in Figure 2. The majority of responses $(54 \%)$ from the faculty described their role as teachers in terms of students' interest. The descriptions included, as a guide to students' learning, a facilitator, a person who can create an engaging environment among others. Some responses (33\%), such as encouraging higher-order thinking, and service instructor for other courses among others, were uncategorized. In the second question, about a third (30\%) of the instructors also decide what to and what not to teach based on students' interests. Descriptions in this category comprised activities to engage students, providing a good undergraduate experience to students, and providing tools to students for solving problems, among others. In this case, the majority $(55 \%)$ of responses fell under the teacher interest category. These responses include prescribed standards and background to other courses among others. Fifteen percent of the responses to this question were uncategorized. In the third question, we also observed that the majority (56\%) of instructors decide how to move on to a new topic based on teacher interest. Responses on this question include the amount of content covered, syllabus, and schedule-driven. Forty-four percent of responses indicated student interest in determining when to move on to a new topic. The responses include based on assessments and students' understanding.

\section{Epistemological Beliefs Based on Classroom Interactions}

Data were analyzed to determine how responses were distributed on the active engagement to the traditional engagement continuum. This section included five questions

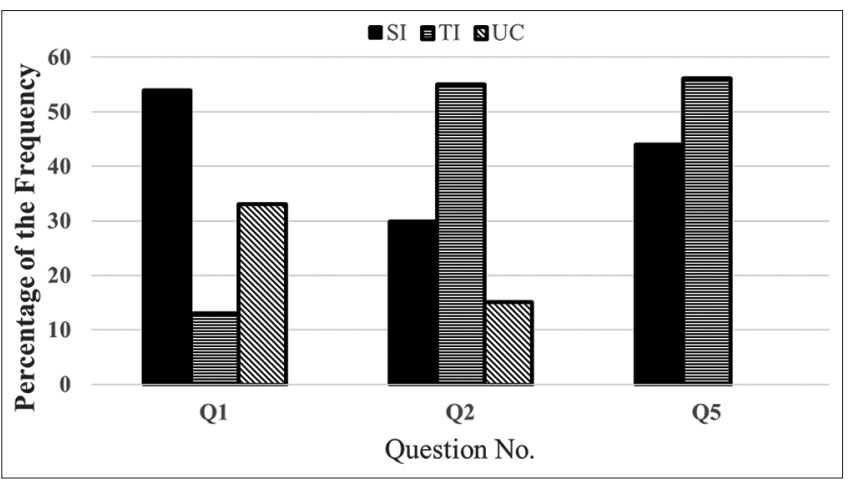

Figure 2: Epistemological beliefs based on student interest versus teacher interest. SI: Student interest; TI: Teacher interest; UC: Uncategorized out of six because the last one was irrelevant. Figure 3 presents these questions and their proportional responses.

How do you describe your role as a teacher (Q1)? For this question, $67 \%$ of the responses indicated beliefs supporting active engagements in the classroom. In this category, responses included a facilitator, a guide, and a person who can create an engaging environment, among others. Only $10 \%$ of responses displayed traditional beliefs. The descriptions in this category include a presenter, an interpreter, and a custodian of knowledge. Twenty-three percent of the responses did not fall into these two categories. These responses include decisionmaker on learning, and builder of student knowledge, among others.

How do your students learn science best (Q3)? On this question, $61 \%$ of responses showed beliefs that aligned with active engagement. These responses included "by being engaged," "doing it," or "having autonomy in their work." Nine percent of responses that displayed traditional beliefs include cannon delivery, textbook, and proper study habits. The rest of the responses were uncategorized.

How do you maximize learning (Q4)? In this category, most of the responses $(66 \%)$ displayed beliefs that support active engagement in students' learning. Responses in this category included group activities, creating an engaging environment, and creating activities that engage students, among others. The rest of the responses to this question were uncategorized, including problem-solving and outside activities.

How do you decide when to move on to a new topic (Q5)? Responses about beliefs for this question were evenly split between active engagement (44\%) and traditional engagement (44\%). Twelve percent of the responses were uncategorized. Responses categorized as active engagement include assessments and student's understanding. The traditional responses include syllabus, calendar-driven, and the amount of content covered.

How do you know when learning is occurring in your class (Q6)? For this question, 56\% of responses had beliefs that displayed active approaches to teaching. Responses included interaction with students in the classroom, classroom

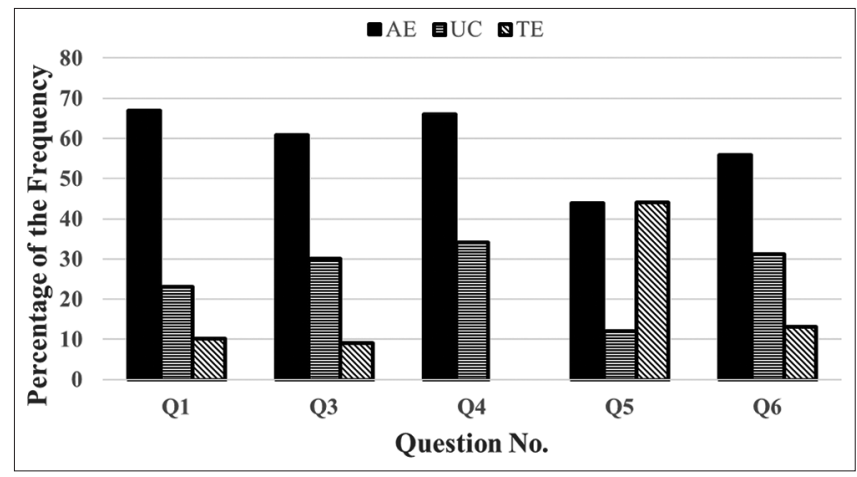

Figure 3: Epistemological beliefs based on classroom interactions. AE: Active engagements; UC: Uncategorized; TE: Traditional engagements 
conversations, and how students engage each other when working on activities. Thirteen percent of responses were categorized in the traditional beliefs category. These responses include lab writing samples and exams. However, $31 \%$ of responses did not fall into either of the two categories.

\section{Epistemological Beliefs Based on Assessment Type}

This analysis sought to describe the nature of faculty beliefs about assessment in general. The responses focused on assessment as either formative or summative. First, all the instructors had beliefs about the importance of formative assessments. These include classroom conversations between teachers and students and among students; responses to clicker questions; ability to ask relevant questions to the teacher and other students; and engagement in process-oriented guided inquiry (Moog, 2013) style activities. In this case, $100 \%$ of the participants encouraged formative assessments. Most of the instructors also mentioned some sort of summative assessment, especially exams and homework assignments. It was clear from our analysis that instructors in this study value both formative and summative assessments. The analysis further showed that formative assessment activities dominated the interview responses. Figure 4 shows the percentage ratio in which formative and summative assessment activities were mentioned.

\section{Comparison of TBI Scores Based on Workshop Attendance}

The second research question is "How does the epistemological beliefs of faculty who participated in a PD workshop compare

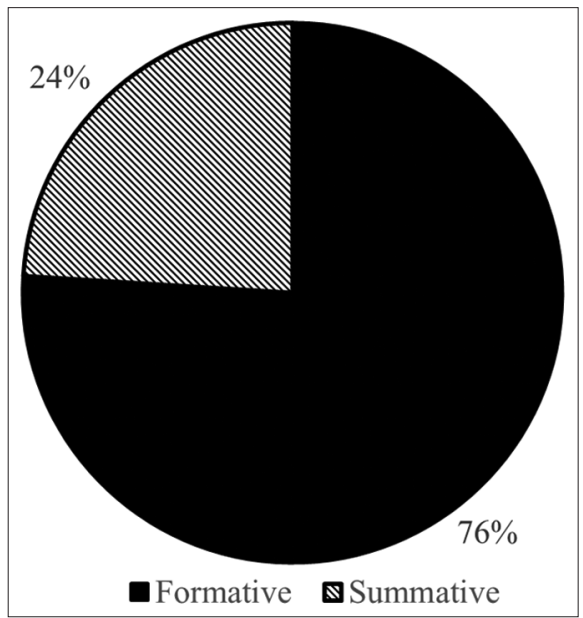

Figure 4: Beliefs about assessment type; percentage of the response frequency

\begin{tabular}{lccc}
\hline \multicolumn{3}{l}{ Table 4: Comparison of treatment and control TBI scores } \\
\hline Test value & Treatment & Control \\
\hline $\mathrm{N}$ & 13 & & 11 \\
$\mathrm{M}$ & $19.9 \pm 2.4$ & & $15.2 \pm 3.1$ \\
$\mathrm{z}$ & & 2.39 & \\
$\rho$ & & $<0.05$ & \\
$\mathrm{~d}$ & & 1.64 & \\
\hline
\end{tabular}

TBI: Teacher beliefs interview with the comparison group?" The main question was, "is there a difference in mean ranks between workshop participants and the comparison group?" The null hypothesis was that there was no difference in mean ranks between these two groups of participants. Table 4 shows results based on this research question. A Mann-Whitney U-test revealed a statistical difference between workshop participants and the comparison group, $\mathrm{z}=2.39, \mathrm{p}<0.05$, with a large effect size of $d=1.64$ (Cohen, 1988). Using these statistics, we rejected the null hypothesis and hence observed a significant difference in mean ranks between participants to the PD workshop and the comparison group. In terms of magnitude, the PD participants' group $(n=13)$ had a mean score of 19.9 , while the comparison group $(n=11)$ had a TBI mean score of 15.2. Five faculty members who were interviewed before and after they participated in the PD were selected for the comparison of pre- and post-scores. Their mean TBI score changed from 15.0 before participation to 18.4 after participation. No inferential statistics were done on these five because the sample size was small.

\section{Epistemology Beliefs and Practice}

The third research question was, "What is the relationship between faculty epistemological beliefs and their teaching practice?" All the 19 faculty members who were interviewed using TBI were also observed as they taught their classes and rated using RTOP. We re-observed the five faculty members from the comparison group after participating in the PD to make 24 faculty teaching observations. The TBI and RTOP scores were compared to determine the relationship between observation scores and epistemological beliefs. The null hypothesis was that there would be no significant linear relationship between epistemological beliefs and practice. The correlation coefficient using Pearson $r$ was $0.73(D F=22, t=5.00$, $\rho=0.000)$. In this case, the null hypothesis was rejected and, therefore, determined that there was a positive linear relationship between faculty epistemological beliefs and practice. Table 5 shows exemplary quotes from TBI and our general description of the classroom activities.

\section{DISCUSSION AND CONCLUSIONS}

The first research question was, "What is the epistemological beliefs of science faculty at a southern US liberal arts college?" The mean TBI score out of 30 was $17.8 \pm 3.55$ with a median score of 18.0 indicating that the science faculty had beliefs consistent with the transitional level according to Luft and Roehrig (2007). Varnava-Marouchou (2007) would describe these beliefs as sophisticated. Therefore, we believe that faculty in this study is capable of facilitating students' learning by providing opportunities for students to develop meaning from the learning process. These results mirror those reported by Addy et al. (2015) on college science faculty with education specialties. Addy et al. found that science faculty with educational specialties displayed beliefs from transition through reform. 


\begin{tabular}{lll}
\hline Table & 5: & TBI and RTOP observation description \\
\hline Name & Sample TBI response & Classroom observation \\
\hline CHM3 & $\begin{array}{l}\text { I think of myself as, I guess, a few different roles. I am an instructor for one. } \\
\text { I am a presenter of important topics in chemistry but I am also a helper on } \\
\text { their way to learn whatever that way is. }\end{array}$ & $\begin{array}{l}\text { Starts with a } 30-35 \text { min straight lecture. Then, he gives } \\
\text { students handouts with problems to solve. He walks around } \\
\text { as the students solve the problems. However, probing is still } \\
\text { limited in his class. }\end{array}$
\end{tabular}

MAT1 I often say in class; you may have heard me say. "Today is a good day to be wrong." Right, so get up there, show me what you got, report out to your group or report to the class and, you know, if you are wrong, we will all be supportive of you, and we will help to find, you know, those mistakes.

BIO2 Some of it is dictated by the schedule. Some of it, I am bending my schedule a little bit because, again, this is the 1st time I have taught this course. So I am learning that, ok we need to stop, and if they are not, they are having trouble with the clicker questions, they are not answering questions correctly that I am asking them, we are having trouble with the in-class activities, then I know to slow down and that we need a little bit more time with this subject.
In his classroom, he ensures the maximization of students' active involvement. He seeks students' understanding through frequent probing. He gives students a lot of freedom on how they approach classroom problems. He also tries to bring together the lesson by asking students to share with the whole class what they have discussed in their groups. Students are given a chance to comment on other students' work.

In his class, students sit in groups of 3 or 4 . He encourages interaction among students by using clicker questions. He also encourages students to discuss questions in their groups. However, the questions are mostly teacher-directed.

TBI: Teacher beliefs interview, RTOP: Reformed Teaching Observation Protocol

In terms of beliefs about classroom engagement, in this study, faculty beliefs demonstrated the dominance of active engagement. This is encouraging because teaching that actively engages students in the learning process improves the meaningmaking process from the instruction (Chi, 2009). A follow-up teacher observation indicated that the instructors were indeed using some of the practices they discussed during the interview. This information is important, especially for the planning of PD activities. Transforming faculty beliefs about student engagement should be among the important aspects of PD.

The second research question is, "What is the impact of participating in professional development on faculty epistemological beliefs?" The post-test only comparison done between the PD workshop participants and the comparison group showed a significant difference between these two groups. This difference may not be entirely attributed to the current workshop since some of the faculty who attended this workshop have attended various types of workshops before this one. However, five participants in this study participated as both comparison groups in the first phase of the study and the PD group in the second phase. Their epistemological beliefs before and after the training changed from the mean score of 15.0-18.4. Further, other factors, such as teaching discipline, tenure promotion, among others did not affect faculty epistemological beliefs; the workshop might have to have contributed to this difference.

The third research question is, "What is the relationship between faculty epistemological beliefs and their teaching practice?" The comparison with teaching practices showed a highly significant correlation between teacher epistemological beliefs and practice. This indicates that faculty with teachercentered beliefs are likely to create teaching practices that promote teacher-centered instructions. Addy et al. (2015) and Jackson (2010) have pointed out that beliefs have the potential to inform practices. Further, Buehl and Fives (2009) emphasized that beliefs are core to the teaching practice. This implies that science educators and colleges need to determine ways by which they can improve faculty epistemological beliefs. Our results and those by Addy (2011) and Addy et al. (2015) indicate that more still needs to be done to improve faculty epistemological beliefs away from transitional to more reformed level.

\section{Implication}

Results from this study have shown that there is still a long way to go to change faculty epistemological beliefs about teaching. These results are consistent, however, with those found by Addy (2011). Further, the results have also shown more student-centered epistemological beliefs for participants of the PD compared to the comparison group. In addition, a positive linear correlation has been observed between studentcentered faculty epistemological beliefs and student-centered practice. Therefore, this study encourages colleges to create intentional activities to boost faculty epistemological beliefs about teaching to, as these results suggest, improve teaching practice. Therefore, it is our belief that the workshop may have contributed to this difference.

\section{Limitation of the Study}

This study is limited in that there was insufficient data about faculty philosophies and practices from the period before workshop attendance because we started data collection after the first workshop had already taken place. Further, there may be a selection effect in that the faculty who chose to go through the faculty development may have been primed to incorporate student-centered teaching even if they had not before.

However, five participants in this study participated as both comparison groups in the first phase of the study and the PD group in the second phase. Researchers were able to follow 
their epistemological beliefs before and after the training. An improvement was observed in their mean scores from 15.0 to 18.4. Further, other factors such as teaching discipline and tenure promotion among others did not affect faculty epistemological beliefs; the workshop seemed to have contributed to this difference.

\section{ACKNOWLEDGMENT}

The researchers would like to thank the faculty who participated in the project without whose contribution this research would have been impossible. This material is based upon work supported by the National Science Foundation under award number DUE-1347645.

\section{REFERENCES}

Addy, T. (2011). Epistemological Beliefs and Practices of Science Faculty with Education Specialties: Combining Teaching Scholarship and Interdisciplinarity. (North Carolina State University). Available from: http://www.repository.lib.ncsu.edu/ir/bitstream/1840.16/6798/1/etd.pdf. [Last accessed on 2019 Sep 13].

Addy, T., Simmons, P., Gardner, G., \& Albert, J. (2015). Research and teaching: A new "class" of undergraduate professors: Examining teaching beliefs and practices of science faculty with education specialties. Journal of College Science Teaching, 44(3), 5-9.

Beach, A., \& Cox, M. (2009). The impact of faculty learning communities on teaching and learning. Learning Communities Journal, 1(1), 7-27.

Berding, F., Rolf-Wittlake, K., \& Buschenlange, J. (2017). Impact of different levels of epistemic beliefs on learning processes and outcomes in vocational education and training. World Journal of Education, 7(3), 103-114.

Brydges, S., Chilukuri, L. Cook, G., Feeley, M., Herbst, M., Tour, E., \& Van Den Endel, L. (2013). Building a faculty learning community at a research university. Currents in Teaching and Learning, 5(1-2), 17-35.

Buehl, M.M., \& Fives, H. (2009). Exploring teachers' beliefs about teaching knowledge: Where does it come from? Does it change? The Journal of Experimental Education, 77(4), 367-408.

Chi, M.T.H. (2009). Active-constructive-interactive: A conceptual framework for differentiating learning activities. Topics in Cognitive Science, 1, 73-105.

Cohen, J. (1988). Statistical Power Analysis for the Behavioral Sciences. $2^{\text {nd }}$ ed. New York: Lawrence Erlbaum Associates.

Fink, D.L. (2003). A Self-Directed Guide to Designing Courses for Significant Learning. San Francisco, CA: Jossey-Bass. p1-36.

Fishbein, M., \& Ajzen, I. (1975). Belief, Attitude, Intention, and Behavior: An Introduction to Theory and Research. Reading, MA: Addison-Wesley.

Fletcher, S.S. (2006). Exploring the Beliefs and Practices of Five Preservice Secondary Science Teachers from Recruitment Through Induction in a University Preparation Program: A Longitudinal Study. (University of Texas at Austin). Available from: http//www.C:/Users/lloyd/ Downloads/Exploring the beliefs and practices_of five preser.pdf. [Last accessed on 2019 Sep 13].

Gabr, H., \& Mohammed, N. (2011). Effect of problem-based learning on undergraduate nursing students enrolled in the nursing administration course. International Journal of Academic Research. International Journal of Academic Research, 3(1), 154-162.

Gallagher, S.A., \& Stepien, W.J. (1992). The effects of problem-based learning on problem-solving. Gifted Child Quarterly, 36(4), 195-200.

Garmon, A.M. (2004). Changing preservice teachers' beliefs/attitudes about diversity: What are the critical factors? Journal of Teacher Education, 55(30), 201-213.

Harris, M., \& Cullen, R. (2008). Learner-centered leadership: An agenda for action. Innovation in Higher Education, 33(1), 21-28.

Hashweh, M.Z. (1996). Effects of science teachers' epistemological beliefs in teaching. Journal of Research in Science Teaching, 33, 47-63.

Ismail, H., Hassan, H., Muhamad, M., Ali, W.Z.W., \& Majid, M. (2013).
Epistemological belief and learning approaches of students in higher institutions of learning in Malaysia. International Journal of Instruction, 6(1), 139-151

Jackson, D.B. (2010). The Impact of Science Teachers' Epistemological Beliefs on Authentic Inquiry: A Multiple-case Study. (Baylor University). Available from: http//www.C:/Users/lloyd/Downloads/dionne_jackson_ edd.pdf. [Last accessed on 2019 Sep 13].

Jones, M.G., \& Carter, G. (2007). Science teacher attitudes and beliefs. In: Abell, S.K., \& Lederman, N. (Eds.), Handbook of Research on Science Education. Mahwah, New Jersey: Lawrence Erlbaum Associates. p1067-1104.

Kagan, D. (1990). Ways of evaluating teacher cognition: Inferences concerning Goldilocks principle. Review of Educational Research, 60, 419-275.

Kember, D. (1997). A reconceptualization of the research into university academics' conceptions of teaching. Learning and Instruction, 7(3), 255-275.

Kember, D., \& Kwan, K. (2000). Lecturers' approaches to teaching and their relationship to conceptions of good teaching. Instructional Science, 28 , 469-490

Luft, J.A., \& Roehring, G.H. (2007). Capturing science teachers' epistemological beliefs: The development of the teacher beliefs interview. Electronic Journal of Science Education, 11(2), 40-63.

Luft, J. A., \& Zhang, C. (2014). The pedagogical content knowledge and beliefs of newly hired secondary science teachers: The first three years. Quimica, 25, 325-331.

Moog, R. (2014). Process guided inquiry. In: McDaniel, M.A., Frey, R.F., Fitzpatrick, S.M., \& Roediger, H.L. (Eds.), Integrating Cognitive Science with Innovative Teaching. St. Louis: Washington University. p147-160. Available from: https://www.openscholarship.wustl.edu/ cgi/viewcontent.cgi?article $=1009 \&$ context $=$ books. [Last accessed on 2019 Sep 13].

Nespor, J. (1987). The role of beliefs in the practice of teaching. Journal of Curriculum Studies, 19(4), 317-328.

Österholm, M. (2010). Beliefs: A theoretically unnecessary construct? Proceedings of The $6^{\text {th }}$ Congress of the European Society for Research in Mathematics Education. p154-163. Available from: http://www.ife.enslyon.fr/publications/edition-electronique/cerme6/wg1-13-osterholm. pdf. [Last accessed on 2019 Sep 13].

Pajares, M.F. (2008). Teachers' beliefs and educational research: Cleaning up a messy construct. Review of Educational Research, 62(3), 307-332.

Pehkonen, E., \& Törner, G. (1996). Mathematical beliefs and different aspects of their meaning. Zentralblatt Für Didaktik Der Mathematik, 28(4), 101-108.

Piburn, M., \& Sawada, D. (1995). Reformed Teaching Observation Protocol: Reference Manual. ACEPT Technical Report, No. IN00-3. p1-41. Available from: http://www.public.asu.edu/ anton1/AssessArticles/ Assessments/Biology\%20Assessments/RTOP\%20Reference $\% 20$ Manual.pdf. [Last accessed on 2019 Sep 13].

Richardson, V. (1996). The role of attitudes and beliefs in learning to teach. In: Sikula, J. (Ed.), Handbook of Research on Teacher Education. $2^{\text {nd }}$ ed. New York: Macmillan. p102-119.

Richlin, L., \& Essington, A. (2004). Overview of faculty learning communities. In: Cox, M.D., \& Richlin, L., (Eds.), Building Faculty Learning Communities: New Directions for Teaching and Learning. San Fransisco, CA: Jossey-Bass. p25-39.

Schoenfeld, A.H. (1983). Beyond the purely cognitive: Belief systems, social cognitions, and metacognitions as driving forces in intellectual performance. Cognitive Science, 7, 329-363.

Schommer, M., Crouse, A., \& Rhodes, N. (1992). Epistemological beliefs and mathematical text comprehension. Journal of Educational Psychology, 84(4), 435-443.

Schramm-Possinger, M. (2015). Pre-service teachers' humanistic vs. custodial beliefs: Before and after the student teaching experience Journal of Education and Training Studies, 4(1), 74-87.

Simmons, P.E., Emory, E. Carter, T. Coker, T, Finnegan, B, Crockett, D. Richardson, L., Yager, R., Craven, J., Tillotson, J., Brunkhorst, H., Twiest, M., Hossain, K., Gallagher, J., Duggan-Haas, D., Parker, J., Cajas, F., Alshannag, Q., McGlamery, S., Krockover, J., Adams, P., Spector, B., LaPorta, T., James, B., Rearden, K., \& Labuda, K. (1999). Beginning teachers: Beliefs and classroom actions. Journal of Research 
in Science Teaching, 36(8), 930-954.

Speer, N.M. (2005). Issues of method and theory in the study of mathematics teachers' professed and attributed beliefs. Educational Studies in Mathematics, 58, 361-391.

Varnava-Marouchou, D. (2007). Teaching and Learning in an Undergraduate Business Context: An Inquiry into Lecturers' Conceptions of Teaching and Their Students' Conceptions of Learning. (The University of Nottingham, UK. Available from: https://www.researchgate.net/ publication/37245732 Teaching and learning in an undergraduate business_context_an_inquiry_into_lecturers'_conceptions_of teaching_and_their_students'_conceptions_of_learning. [Last accessed on 2019 Sep 13]. 